\title{
Dedang Songke Sebagai Home Based Production
}

\author{
Desideria Alfani Dugis*, I Wayan Suwena, Aliffiati \\ Program Studi Antropologi, Fakultas Ilmu Budaya, Unud \\ [desidugis870@gmail.com] \\ Denpasar, Bali, Indonesia \\ *Corresponding Author
}

\begin{abstract}
Dedang songke or the activity of weaving traditional cloth (songke) is a tradition that is still widely practiced by housewives as the ancestral heritage of Manggarai Community, especially in the Orchard of Ringkas. The objectives of this study are (1) to find out the reasons why women in Ringkas Orchard made dedang songke as home based production (2) to find out the implications of dedang songke as home based production for the lives of the weavers, their families, and the people of Ringkas Orchard. This study uses the need achievement theory and the rational choice theory. While the concept used in this study are dedang songke, handicraft industry, and home based production. In this study, the research method used was qualitative with two data sources namely primary data and secondary data, through observation and interview for collecting the data. The results found from the research show that the background of the housewives in Ringkas Orchard works as weavers because of internal and external factors. Internal factors include: the desire to help husband to fulfill family needs, the desire to get recognition and the desire to continue their ancestral's heritage. While external factors include: insufficient employment, inadequate farming/gardening production, and educational factor. The struggle of women in dedang songke handicraft industry as home based production has implications for the individual weavers, their families, and communities.
\end{abstract}

Keywords: home based production, dedang songke, weavers.

\begin{abstract}
Abstrak
Dedang songke atau aktivitas menenun kain tradisional (songke) merupakan sebuah tradisi yang masih banyak dilakukan oleh ibu rumah tangga sebagai warisan leluhur atau nenek moyang masyarakat Manggarai khususnya di Dusun Ringkas. Adapun tujuan dari penelitian ini antara lain (1) untuk mengetahui alasan mengapa perempuan di Dusun Ringkas menjadikan dedang songke sebagai home based production (2) untuk mengetahui implikasi dedang songke sebagai home based production bagi kehidupan penenun, keluarga dan masyarakat di Dusun Ringkas.Teori yang digunakan dalam penelitian ini adalah teori need achievement dan teori pilihan rasional. Sedangkan konsep yang digunakan antara lain dedang songke, industri kerajinan dan home based production. Dalam penelitian ini, metode penelitian yang digunakan adalah kualitatif dengan dua sumber data, yaitu primer dan sekunder dengan teknik pengumpulan data melalui observasi dan wawancara. Hasil yang ditemukan dalam penelitian memperlihatkan bahwa latar belakang ibu rumah tangga di Dusun Ringkas berprofesi sebagai penenun karena adanya faktor internal dan eksternal. Faktor internal meliputi: keinginan membantu suami dalam memenuhi kebutuhan keluarga, keinginan untuk mendapat pengakuan dan keinginan untuk meneruskan warisan leluhur. Sedangkan faktor eksternal meliputi: kurangnya lapangan pekerjaan, pengahasilan pertanian/kebun tidak mencukupi, faktor pendidikan. Bergelutnya perempuan dalam industri kerajinan
\end{abstract}


dedang songke sebagai home based production berimplikasi terhadap individu penenun, keluarga dan masyarakat.

Kata kunci: home based production, dedang songke, penenun.

\section{PENDAHULUAN}

Pengerahan sumber daya ekonomi yang dimiliki rumah tangga, telah menuntut wanita sebagai istri dapat menopang ketahanan ekonomi keluarga (Samadara, dkk 2018:44). Upaya menjaga kestabilan dan meningkatkan ekonomi keluarga biasanya perempuan atau isteri keluarga petani di pedesaan ikut serta dalam membantu suami sebagai pencari nafkah utama untuk menambah penghasilan dalam keluarga meskipun kontribusinya seringkali diabaikan. Biasanya sektor-sektor yang seringkali dimasuki oleh para perempuan di pedesaan tidak jauh kaitannya dengan urusan domestik yang bertujuan agar tugas sebagai isteri dan ibu rumah tangga tetap berjalan.

Industri kerajinan adalah salah satu pekerjaan yang banyak ditekuni oleh kaum perempuan terutama yang berada di daerah pedesaan. Industri kerajinan merupakan salah satu industri yang terikat pada rumah tangga karena kegiatan produksi berlangsung di rumah atau di sekitar rumah (home-based production). Industri rumah tangga kerajinan merupakan kegiatan ekonomi yang ideal bagi kaum perempuan karena industri semacam ini dapat memadukan tugas perempuan (reproduktif) sebagai ibu/istri dengan tugas (produktif) sebagai pencari nafkah (Abdullah, 2001: 182183). Di Indonesia terdapat banyak kebudayaan seni kerajinan salah satunya adalah kebudayaan tenun yang tersebar hingga keseluruh pelosok Nusantara (Sholihah, 2016:1). Salah satu diantaranya terdapat di Dusun Ringkas, Desa Perak, Kecamatan Cibal, Kabupaten Manggarai-NTT.

Sebagian besar perempuan di Dusun Ringkas rata-rata berprofesi sebagai penenun, yakni 80\% dari 292 perempuan. Kegiatan menenun dilaksanakan secara manual dan tradisional serta merupakan kegiatan kaum wanita (Dima dalam Murniati dkk, 2016:68). Mulanya dedang songke hanya dilakukan sebagai suatu tradisi yang diwariskan oleh nenek moyang. Namun, seiring berjalannya waktu menjadi sebuah pekerjaan atau mata pencaharian hidup yang bisa menghasilkan uang. Dalam perkembanganya juga terjadi perubahan pada fungsi, yakni kain tenun tersebut tidak hanya digunakan sebagai fungsi sakral yaitu perlengkapan upacara maupun ritual-ritual tetapi juga profan yaitu untuk memenuhi keperluan hidup sehari-hari (Nurcahyani, 2018:61).

Berprofesi sebagai penenun adalah salah satu upaya perempuan sebagai istri dan ibu rumah tangga di Dusun Ringkas untuk membantu mempertahankan dan meningkatkan ekonomi keluarga. Aktivitas dedang songke yang dilakukan oleh penenun di Dusun Ringkas menarik untuk diteliti dengan judul Dedang Songke Sebagai Home Based Production.

Masalah yang dikaji dalam penelitian ini dapat dirumuskan dalam bentuk pertanyaan sebagai berikut: Mengapa perempuan di Dusun Ringkas menjadikan dedang songke sebagai home based production?, Bagaimana implikasi dedang songke sebagai home based production bagi kehidupan penenun, keluarga, dan masyarakat di Dusun Ringkas?

Tujuan yang dicapai dalam penelitian ini adalah sebagai berikut: Untuk mengetahui alasan mengapa perempuan di Dusun Ringkas menjadikan dedang songke sebagai home based production. Serta untuk mengetahui implikasi dedang songke 
sebagai home based production bagi kehidupan penenun, keluarga dan masyarakat di Dusun Ringkas.

\section{METODE}

Penelitian ini menggunakan metode kualitatif yang dilakukan di Dusun Ringkas Desa Perak, Kecamatan Cibal, Kabupaten Manggarai-NTT. Teknik pengumpulan data dilakukan dengan cara observasi, wawancara dan studi kepustakaan.

\section{HASIL DAN PEMBAHASAN}

\section{Alasan Perempuan Melakukan Dedang Songke}

a. Keinginan Membantu Suami dalam Memenuhi Kebutuhan Keluarga

Tidak dapat kita pungkiri bahawasannya manusia itu membutuhkan sandang, pangan dan papan. Tanpa adanya pendapatan maka manusia tidak akan dapat bertahan dalam memenuhi kebutuhan hidupnya. Oleh karenanya pendapatan sangatlah menjadi kebutuhan yang sangat vital bagi manusia. Dengan memiliki pendapatan maka manusia dapat memenuhi kebutuhannya untuk mempertahankan hidup (Putri, 2015:61).

Dalam rangka memenuhi semua kebutuhan diperlukan kerjasama antara anggota keluarga. Artinya tidak hanya suami yang bekerja sebagai pencari nafkah utama dalam keluarga tetapi istri juga turut mengambil bagian dalam rangka menambah pendapatan keluarga atau rumah tangga. Oleh karena itu, sebagian besar perempuan di Dusun Ringkas bekerja sebagai usaha menambah penghasilan dalam keluarga sehingga munculah keinginan dari dalam diri perempuan untuk membantu suami melalui dedang songke setiap hari. Umumnya misi/harapan yang ingin dicapai oleh rata-rata tenaga kerja perempuan di pedesaan adalah alasan ekonomi yaitu menambah pendapatan keluarga (Handayani, 2010 : 32). Wanita bekerja pada industri tenun karena adanya tuntutan ekonomi/ingin membantu perekonomian keluarga/ pendapatan suami (Rioeh , 2017:73). Tenun sudah dijadikan sebagai kegiatan usaha atau industri rumah tangga dan ikut berperan dalam pengembangan ekonomi rakyat di daerah (Husen dalam Sitanggang, 2016:142).

\section{b. Keinginan Untuk Mendapat} Pengakuan

Pekerjaan dapat diartikan sebagai identitas diri dan akan menimbulkan kepuasan diri apabila hasil pekerjaan tersebut diapresiasi, diakui dan dihargai oleh orang-orang yang berada di sekelilingnya, yakni keluarga dan masyarakat. Manusia memiliki kebutuhan untuk dihargai, misalnya rasa hormat, harga diri, pujian, dsb. Pemenuhan akan harga diri bisa membawa perasaan percaya pada diri sendiri, nilai, kekuatan, perasaan dibutuhkan dan bermanfaat bagi orang lain (Rahaju dkk, 2012:83). Demikian pun halnya dengan penenun di Dusun Ringkas, keterampilan menenun yang dilakukan bertujuan untuk mendapat pengakuan dari keluarga dan masyarakat atas pekerjaan dedang songke.

\section{c. Keinginan Untuk Meneruskan Warisan Leluhur}

Berprofesi sebagai penenun songke tidak semata-mata dilakukan sebagai suatu pekerjaan biasa melainkan pekerjaan yang dilakukan atas dasar keinginan yang berasal dari dalam diri perempuan untuk meneruskan warisan leluhur. Tenun sebagai salah satu warisan budaya tinggi (heritage) merupakan kebanggaan bangsa Indonesia, dan mencerminkan jati diri bangsa. Oleh sebab itu, tenun baik dari segi teknik produksi, desain dan produk yang 
dihasilkan harus dijaga dan dilestarikan keberadaannya, serta dimasyarakatkan kembali penggunaannya (Rahayulan dalam Aminy, 2019:77). Bagi para penenun dan penduduk di Dusun Ringkas menenun adalah salah satu warisan budaya yang mencerminkan jati diri masyarakat setempat yang telah diwariskan oleh leluhur atau generasi sebelumnya sehingga patut dilestarikan dan dipertahankan.

\section{d. Kurangnya Lapangan Pekerjaan}

Salah satu faktor yang menyebabkan perempuan atau ibu rumah tangga memilih untuk menenun songke yaitu karena kurangnya lapangan pekerjaan. Para penenun yang terdiri dari ibu rumah tangga tersebut sangat memanfaatkan keterampilan menenun yang dimiliki sebagai suatu strategi dan usaha untuk mempertahankan dan meningkatkan ekonomi keluarga.

Lapangan pekerjaan yang sangat sulit didapatkan dewasa ini khusunya bagi masyarakat yang berada di wilayah pedesaan seperti Dusun Ringkas dapat terpecahkan dengan terjunnya perempuan dalam dedang songke. Dengan kata lain, industri kerajinan ini telah menyerap banyak tenaga kerja sehingga mengurangi tingkat pengangguran (Amirmahmuda dalam Waluyati dkk, 2016:68). Menjadi seorang penenun songke seyogianya menjadi lapangan pekerjaan yang patut diperhitungkan.

\section{e. Pengahasilan Pertanian/Kebun Tidak Mencukupi}

Hasil pertanian seringkali hanya untuk dikonsumsi sendiri mengingat hasilnya ini memang sedikit atau kurang melimpah. Pemilikan tanah pertanian per kapita yang sempit, menyebabkan berkurangnya kesempatan atau peluang untuk bekerja bagi pria maupun wanita. Walaupun Dusun Ringkas merupakan salah wilayah dengan penghasilan kemiri dan kopi terbanyak di wilayah Cibal namun tanaman tersebut ada saat musimmusim tertentu. Penghasilan kopi dan kemiri yang hanya mengenal musiman tersebut tentunya belum bisa mencukupi kebutuhan keluarga. Sebagai solusi untuk mendapat penghasilan tambahan dalam keluarga maka perempuan memilih untuk dedang songke. Oleh sebab itu keputusan untuk mengurusi kebun hanya dilakukan oleh suami sedangkan istri menenun setiap hari di rumah atau sekitar rumah.

\section{f. Faktor Pendidikan}

Menenun adalah salah satu pekerjaan yang bisa dilakukan oleh siapa pun tanpa melalui pendidikan formal karena dalam proses produksinya lebih mengutamakan ketekunan, keterampilan, ketelitian dan imajinasi . Oleh sebab itu, tinggi rendahnya pendidikan formal tidak menjadi persyaratan mutlak untuk bekerja pada sektor ini (Marlina, 2003:65). Kenyataan ini tentunya menguntungkan sebagian besar penenun yang memiliki tingkat pendidikan Sekolah Dasar memilih untuk menekuni profesi sebagai penenun, karena dengan berbekal keterampilan dan ketelitian mereka bisa menghasilkan selembar kain tenun songke.

\section{Implikasi dedang songke sebagai home based production bagi kehidupan penenun, keluarga, dan masyarakat di Dusun Ringkas}

\section{a. Fisik Penenun}

Beberapa jenis pekerjaan akan memerlukan sikap dan posisi tertentu yang kadang-kadang cenderung untuk tidak mengenakkan. Kondisi kerja seperti ini memaksa pekerja-pekerja selalu berada pada sikap dan posisi kerja yang aneh dan kadang-kadang juga harus berlangsung dalam waktu yang lama. Hal ini tentu saja akan mengakibatkan pekerja cepat lelah, membuat banyak 
kesalahan atau menderita cacat tubuh (Mufti dkk, 2013:63).

Memanfaatkan teknologi tradisional dalam proses menenun dapat mempengaruhi keadaan fisik karena seluruh aktivitas tersebut murni menggunakan tenaga manusia. Menenun merupakan salah satu pekerjaan yang cukup sulit karena selain menuangkan ide-idenya, fisik pun turut bekerja didalamnya. Kegiatan menenun yang dilakukan setiap hari berpengaruh pada kondisi fisik atau anggota tubuh penenun seperti pinggang, mata, tangan dan kaki.

\section{b. Ekonomi Keluarga}

Bergelutnya perempuan dalam dedang songke sebagai industri rumah tangga merupakan suatu usaha yang mampu mempertahankan dan meningkatkan ekonomi keluarga. Penghasilan perempuan sebagai penenun membantu meringankan kebutuhan dalam keluarga diantaranya untuk keperluan adat, arisan, pembangunan, sekolah/kuliah dan pemenuhan kebutuhan keluarga di dapur seperti untuk membeli beras. Artinya, sebagian kebutuhan keluarga dapat terpenuhi dengan memanfaatkan penghasilan yang diperoleh dari dedang songke. Kerajinan tenun tradisional tersebut mempunyai potensi untuk dapat menampung banyak tenaga kerja, menopang perekonomian masyarakat, dan pada gilirannya dapat meningkatkan kesejahteraan masyarakat (Setiawan dan Suwarningdyah, 2014:354).

c. Mempertahankan Warisan Budaya

Melalui aktivitas menenun setiap hari serta mempertahankan dan menggunakan motif-motif asli Ringkas merupakan suatu cara untuk menunjukkan bahwa masyarakat setempat menyadari pentingnya melestarikan dedang songke. Walaupun sudah hidup di zaman modern dan serba pabrikasi tetapi para penenun tetap mempertahankan warisan yang diturunkan oleh nenek moyang yakni mempertahankan alat tenun tradisional. Alat tenun tersebut menjadi salah satu modal yang membuat penenun tetap mempertahankan kualitas tenunanya.

\section{d. Mempererat Tali Persatuan dan Gotong Royong}

Dalam kehidupan sehari-hari hal tersebut ditunjukkan oleh perempuan saat melakukan aktivitas dedang songke. Pertama, pidik hingga penara. Kedua, meminjamkan benang kepada penenun lainnya. Ketiga, disela-sela waktu istirahat pada sore hari seringkali para penenun berkumpul di satu tempat, biasanya pada salah satu rumah atau natas untuk bertukar cerita sambil membagikan dan menikmati makanan seperti ubi, pisang, jagung, sirih pinang, tuak dan sebagainya. Kelima, saling mempromosikan hasil tenunan penenun lainnya kepada konsumen, kerabat, kenalan atau pelanggan.

\section{SIMPULAN}

Faktor yang melatarbelakangi penenun di Dusun Ringkas menjadikan dedang songke sebagai home based production, yakni karena adanya keinginan membantu suami dalam memenuhi kebutuhan keluarga, keinginan mendapat pengakuan dan keinginan meneruskan warisan leluhur, kurangnya lapangan pekerjaan, penghasilan pertanian/kebun tidak mencukupi dan faktor pendidikan.

Menenun berimplikasi terhadap pribadi penenun, keluarga dan masyarakat disekitarnya, yakni berpengaruh terhadap ekonomi keluarga dan membuka/memperluas lapangan pekerjaan khususnya bagi kaum perempuan, dapat mempertahankan warisan budaya, mempererat tali 
persatuan/gotong-royong dan fisik penenun.

\section{REFERENSI}

Abdullah, Irwan. 2001. Seks, Gender dan Reproduksi Kekuasaan. Yogyakarta: Tarawang Press.

Aminy, Muhammad Habibullah. 2019. "Faktor-Faktor yang Mempengaruhi Minat Pembeli Kain Tenun di Desa Sukarara Kecamatan Jonggat Kabupaten Lombok Tengah". Mataram. Jurnal Kompetitif: Media Informasi Ekonomi Pembangunan, Manajemen dan Akuntansi Volume 5, No.1:75-88.

Handayani. M. Th. 2010. "Sumbangan Pendapatan Ibu Perajin Gula Kelapa Terhadap Pendapatan Rumah Tangga Petani". Jurnal Studi Gender, Volume x, No. 1:2843.

Marlina, B. Yuli. 2003. "Perkembangan Kerajinan Tenun Songket di Desa Sukarara Tahun 1980-1990”. S1 Jurusan Antropologi, Fakultas Sastra, Universitas Udayana.

Mufti, Dessi dkk. 2013. "Kajian Postur Kerja pada Pengrajin Tenun Songket Pandai Sikek". Sumatera. Jurnal Ilmiah Teknik Industri, Volume 12, No. 1:62-72.

Murniati dan Takandjanji, Mariana. 2016. "Analisi Usaha Tenun Ikat Berbasis Pewarna Alami di Kabupaten Sumba Timur". Bogor. Jurnal Dinamika Kerajinan dan Batik, Volume 33, No.1:67-84.

Nurcahyani, Lisyawati. 2018. "Strategi Pengembangan Produk Kain Tenun Ikat Sintang”. Kalimantan. Jurnal
Pendidikan dan Kebudayaan, Volume 3, No.1: 56-71.

Putri, Emmita Devi Hari. 2015. "Upaya Desa Gamplong Sebagai Desa Wisata Industri Alat Tenun Bukan Mesin Dalam Meningkatkan Pendapatan Masyarakat". Yogyakarta. Jurnal Khasanah Ilmu, Volume 6, No.1:57-64).

Rahaju, Endang Edi dkk. 2012. "Motivasi Wanita Bekerja dan Pengaruhnya Terhadap Kontribusi Pendapatan Keluarga". Madiun. Jurnal Ekomaks, Volume 1, No.2:80-94.

Rioeh, I. D. S. P. dkk. 2017. "Studi Tentang Pekerja Wanita di Kota Palu, Studi Kasus pada Ibu Rumah Tangga di Industri Tenun". Palu. Jurnal Katalogis, Volume 5, No. 7: 69-79.

Samadara, Selfesina dkk. 2018. "Pemberdayaan Perempuan Pengrajin Tenun Ikat di Kampung Prai Ijing, Desa Tebar, Kecamatan Kota, Kabupaten Sumba BaratNTT Untuk Meningkatkan Perekonomian Keluarga dan Mendukung Pengembangan Pariwisata Daerah". Kupang. Jurnal Akuntansi, Keuangan dan Audit, Volume 3, No. 1: 44-53.

Setiawan, Budiana dkk. 2014. "Strategi Pengembangan Tenun Ikat Kupang Provinsi NTT". Kupang. Jurnal Pendidikan dan Kebudayaan, Volume 20, No. 3:353-367.

Sholihah, Mar'Atun. 2016. “Kerajinan Tenun Tembe Nggoli di Desa Ranggo, Kecamatan Pajo, Kabupaten Dompu, Nusa Tenggara Barat". S1 Jurusan Pendidikan Seni 
Rupa, Fakultas Bahasa dan Seni, Universitas Negeri Yogyakarta.

Sitanggang, Arinals Rohana. 2016.

"Pemberdayaan Kelompok Industri

Rumah Tangga Sarung Tenun Samarinda Oleh Dewan Kerajinan Nasional Kota Samarinda". Samarinda. Jurnal Pembangunan Sosial, Volume 4, No. 2:141-153.

Waluyati, S. Artati, dkk. 2016. "Analisis Upaya-Upaya Pengrajin Tenun Songket Dalam Mempertahankan Kelangsungan Usaha Di Desa Sudimampir Kecamatan Indralaya Kabupaten Ogan Ilir". Palembang. Jurnal Profit, Volume 3, No. 1:6172. 